\title{
Cytoplasmic Forkhead Box M1 (FoxM1) in Esophageal Squamous Cell Carcinoma Significantly Correlates with Pathological Disease Stage
}

\author{
Marco K. C. Hui - Kwok Wah Chan • John M. Luk • Nikki P. Lee • \\ Yvonne Chung • Leo C. M. Cheung • Gopesh Srivastava • \\ Sai Wah Tsao $\cdot$ Johnny C. Tang $\cdot$ Simon Law
}

Published online: 6 October 2011

(c) The Author(s) 2011. This article is published with open access at Springerlink.com

\begin{abstract}
Esophageal cancer is a deadly cancer with esophageal squamous cell carcinoma (ESCC) as the major type. Until now there has been a lack of reliable prognostic markers for this malignancy. This study aims to investigate the clinical correlation between Forkhead box M1 (FoxM1) and patients' parameters in ESCC.

Methods Immunohistochemistry was performed to investigate the expression and localization of FoxM1 in 64 ESCC tissues and 10 nontumor esophageal tissues randomly selected from 64 patients before these data were used for clinical correlations.

Results Cytoplasmic and nuclear expressions of FoxM1 were found in 63 and 16 of the 64 ESCC tissues, respectively. Low cytoplasmic expression of FoxM1 was correlated with early pathological stage in ESCC $(P=0.018)$, while patients with nuclear FoxM1 were younger in age
\end{abstract}

M. K. C. Hui - N. P. Lee - Y. Chung ·

L. C. M. Cheung $\cdot$ S. Law $(\bowtie)$

Department of Surgery, Queen Mary Hospital,

The University of Hong Kong, Pokfulam, Hong Kong

e-mail: slaw@hkucc.hku.hk

K. W. Chan - G. Srivastava

Department of Pathology, The University of Hong Kong,

Pokfulam, Hong Kong

J. M. Luk

Department of Pharmacology and Surgery, National University

Health System, Singapore, Singapore

S. W. Tsao

Department of Anatomy, The University of Hong Kong,

Pokfulam, Hong Kong

J. C. Tang

Department of Applied Biology and Chemical Technology,

Hong Kong Polytechnic University, Hung Hom, Hong Kong than those without nuclear expression $(P<0.001)$. Upregulation of FoxM1 mRNA was found in five ESCC cell lines (HKESC-1, HKESC-2, HKESC-3, HKESC-4, and SLMT-1) when compared to non-neoplastic esophageal squamous cell line NE-1 using quantitative polymerase chain reaction (qPCR). Except for HKESC-3, all studied ESCC cell lines demonstrated a high expression of FoxM1 protein using immunoblot. A high mRNA level of FoxM1 was observed in all of the ESCC tissues examined when compared to their adjacent nontumor tissues using qPCR.

Conclusion Cytoplasmic FoxM1 was correlated with pathological stage and might be a biomarker for advanced ESCC.

\section{Introduction}

Forkhead box M1 (FoxM1) is a member of the Forkhead transcription factor family, which is evolutionarily conserved and is defined by having a common DNA-binding domain called Forkhead or winged-helix domain [1]. The FOXM1 gene is located on chromosome 12 12p13.3 [2]. It is involved in an array of biological processes, including metabolism and development, cell proliferation, apoptosis and invasion, longevity, and cancer [3]. FoxM1 has high expression in fetal tissues with active cell proliferation and its expression is negligible in differentiated cells [4]. It regulates the cell cycle by modulating the transcription of various cell cycle-related genes essential for G1-S and G2-M progression, chromosome stability, and segregation, including p $27^{\mathrm{kip} 1}$, cyclin B1, and cyclin D [5-8]. Recently, FoxM1 has been linked to tumorigenesis and progression of certain cancers. Recurrent DNA copy number alterations (CNA) were reported in an array-based comparative 
genome hybridization study of malignant peripheral nerve sheath tumor (MPNST). This gain/loss in copy number of FOXM1 is associated with survival in MPNST [2]. Upregulation of FoxM1 expression is found in basal cell carcinomas [9], glioblastomas [10], non-small-cell lung cancers [11], and breast cancers [12, 13]. Mice with FoxM1 conditionally deleted from hepatocytes were highly resistant to liver tumor induction by phenobarbital and diethylnitrosamine [14]. Moreover, expression of the FoxM1 transgene in mice increased with the size of the colorectal tumors while conditional FoxM1 knockout mice showed reduced growth of colorectal tumors [6]. These results suggest a role for FoxM1 in tumor initiation and progression [4]. To our knowledge, no study has investigated the clinical significance of FoxM1 in esophageal squamous cell carcinoma (ESCC), which is a major type of esophageal cancer [15]. The aim of this present study was to investigate the prognostic significance of FoxM1 in ESCC.

\section{Materials and methods}

Human esophageal cell lines

Five human ESCC cell lines, HKESC-1, HKESC-2, HKESC-3, HKESC-4 and SLMT-1, and one human nonneoplastic esophageal squamous cell line, NE-1, were used in this study. These cell lines were previously established by our team [16-20]. NE-1 cells were cultured in keratinocyte-SFM medium supplemented with bovine pituitary extract and human recombinant epidermal growth factor (Invitrogen, Carlsbad, CA). HKESC-1 and HKESC-4 cells were maintained in Minimum Essential Medium (MEM) medium (Invitrogen) with 10\% heat-inactivated fetal bovine serum (FBS) (Invitrogen) and $1 \%$ penicillin and streptomycin (P/S) (Invitrogen). HKESC-2, HKESC-3, and SLMT-1 cells were cultured in MEM medium with $20 \%$ FBS and $1 \% \mathrm{P} / \mathrm{S}$. All cell lines were maintained in a humidified atmosphere at $37^{\circ} \mathrm{C}$ containing $5 \% \mathrm{CO}_{2}$.

\section{Patients and clinical specimens}

We recruited 64 ESCC patients who had undergone esophagectomy between 1997 and 2005 at the Department of Surgery, Queen Mary Hospital, Hong Kong. Consent to use clinical specimens for this study was obtained from the Institutional Review Board of The University of Hong Kong/Hospital Authority Hong Kong West Cluster (HKU/ HA HKW IRB). There were 47 men and 17 women and the mean age was 64.6 years (range $=40-87$ years). None of the patients had received neoadjuvant chemotherapy or radiotherapy before esophagectomy. Data of patient demographics, histopathology, and long-term follow-up were captured in a prospectively collected database. Specimens of primary tumor and nontumor tissues obtained from near the proximal resection margins were stored at $-80^{\circ} \mathrm{C}$ and retained for laboratory studies and subsequent analyses. The site and size of the tumors were recorded. Standard tissue blocks were prepared by fixing the specimens in $10 \%$ formalin before embedding in paraffin wax. Five-micron sections were prepared and stained with hematoxylin and eosin for light microscopy. Stained sections were reviewed and tumors were graded according to the criteria of the World Health Organization (WHO). Cancers were staged according to TNM classification.

Reverse transcription (RT) and quantitative polymerase chain reaction $(\mathrm{qPCR})$

The expression of FoxM1 mRNA in esophageal cell lines and clinical specimens was determined using qPCR. RNA was extracted using TRIzol reagent (Invitrogen), according to manufacturer's instructions. RT and qPCR were performed as described [21, 22]. Five hundred nanograms of RNA was reverse-transcribed into cDNA using the SuperScript III First-Strand Synthesis System for RT-PCR kit (Invitrogen), following the manufacturer's protocol. cDNA $(0.3$ and $0.6 \mu \mathrm{g})$ from cultured cells and tissues was used for qPCR using Platinum Quantitative PCR SuperMix-UDG w/ROX (Invitrogen) and FoxM1-specific primers (forward: 5'-ACC CAA ACC AGC TAT GAT GC-3' and reverse: $5^{\prime}$-GAA GCC ACT GGA TGT TGG AT-3'). $\beta$-Actin was used as an internal control in a parallel experiment, using its specific primers (forward: $5^{\prime}$-CCA TCA TGA AGT GTG ACG TG-3' and reverse: 5'-ATC CAC ATC TGC TGG AAG GT-3'). qPCR was performed using an ABI PRISM 7700 Sequence Detection System (Applied Biosystems, Carlsbad, CA). Each sample was performed in at least duplicates.

Immunoblot

The protein level of FoxM1 in esophageal cell lines was detected using immunoblot as described [23, 24]. Briefly, cultured cells were washed twice with ice-cold $1 \times$ phosphate-buffered saline (PBS, pH 7.4). Ice-cold cell lysis buffer (Cell Signaling Technology, Danvers, MA) was added to cell monolayers to extract proteins by scraping. Cell lysates were left on ice for $15 \mathrm{~min}$ before being centrifuged at $13,200 \mathrm{rpm}$ for $15 \mathrm{~min}$ at $4^{\circ} \mathrm{C}$. Protein concentration was estimated using Bradford Protein Assay solution (Bio-Rad, Hercules, CA). Following the addition of $6 \times$ sample buffer to the cell lysates, $25 \mu \mathrm{g}$ of protein was resolved onto an $8 \%$ sodium dodecyl sulfate (SDS) polyacrylamide gel at room temperature before the transfer of proteins onto the polyvinylidene fluoride (PVDF) membrane for $2.5 \mathrm{~h}$ at $4^{\circ} \mathrm{C}$. After 
blocking with 5\% skimmed milk in Tris-buffered saline with Tween-20 (TBST) at room temperature for $2 \mathrm{~h}$, membranes were probed with polyclonal rabbit anti-FoxM1 antibody (Santa Cruz Biotechnology, Santa Cruz, CA) at 1:1,500 overnight at $4{ }^{\circ} \mathrm{C}$. Monoclonal mouse anti- $\beta$-actin antibody (Sigma-Aldrich, St Louis, MO) at 1:10,000 was used as a loading control. After washing with TBST, membranes were incubated with either goat anti-rabbit (Zymed, Carlsbad, CA) (1:7,000 for detecting anti-FoxM1 antibody) or goat anti-mouse (Zymed) (1:20,000 for detecting anti- $\beta$-actin antibody) secondary antibodies conjugated with horseradish peroxidase (HRP) for $1 \mathrm{~h}$ at room temperature. Following washing with TBST, signals were visualized using ECL Plus Western blotting reagent pack (GE Healthcare Biosciences, Piscataway, NJ). The apparent molecular weight of FoxM1 and $\beta$-actin on gels was 100 and $42 \mathrm{kDa}$, respectively.

\section{Immunohistochemistry}

Five-micron sections from tumors and nontumor tissues were prepared and mounted on glass slides for immunohistochemistry as previously described [23, 25, 26]. Sections were deparaffinized and rehydrated. Antigen retrieval was performed by heating sections in $0.1 \mathrm{M}$ citrus buffer (pH 6.0) in a microwave for $10 \mathrm{~min}$. Endogenous peroxidase activities were blocked by incubating sections with $3 \%$ hydrogen peroxide at room temperature for $20 \mathrm{~min}$. After washing with TBS ( $\mathrm{pH} 7.6$ ), nonspecific binding sites were blocked with $10 \%$ normal goat serum (Dako, Glostrup, Denmark) in TBST at room temperature for $1 \mathrm{~h}$. Sections were incubated with anti-FoxM1 antibody at 1:600 overnight at $4^{\circ} \mathrm{C}$. After washing with TBS, sections were incubated with anti-rabbit-labeled polymer-HRP provided in EnVision + System-HRP (Dako) at room temperature for $45 \mathrm{~min}$ to detect the primary antibody. Signals were visualized by incubating sections with liquid
$\mathrm{DAB}+$ (diaminobenzidine) (Dako) before counterstaining with hematoxylin. A colorectal carcinoma section from the tissue microarray was used as a positive control (Fig. 1a), while normal goat serum as a substitution for anti-FoxM1 antibody was used as a negative control (Fig. 1b). Stained sections were examined by Dr. Chan under light microscope. The expression of cytoplasmic FoxM1 was evaluated according to the methodology of Liu et al. [10] with modifications. The expression of FoxM1 was categorized according to the percentage of cancer cells stained positive with anti-FoxM1 antibody (score from 0 to 3 , where $0 \leq 5 \%, 1=6-25 \%, 2=26-50 \%$, and $3 \geq 51 \%)$ and the intensities of the immunostain $(1+, 2+, 3+)$. A weighted index score (0-9) was calculated for each section by multiplying the values of these two categories. For example, the weighted index score should be 6 if $30 \%$ of cancer cells were stained $($ score $=2$ ) with strong signals (score $=3$ ). For cytoplasmic FoxM1 expression, tumors were further grouped into a low-expression group (weighted index score $=0-4$ ) and a high-expression group (weighted index score $=5-9$ ). For nuclear FoxM1, its expression segregated the tumors into an "absence" group or a "presence" group.

\section{Statistical analysis}

Data are expressed as mean \pm SEM. Pearson's $\chi^{2}$ test was used to assess the correlations between immunohistochemical data and categorical clinicopathological characteristics. The Kaplan-Meier method was used for survival analysis, and the differences in survival were estimated using the log-rank test. A $P$ value of less than 0.05 was considered statistically significant. All statistical analyses were performed using SPSS 12.0 for Windows (SPSS, Inc., Chicago, IL).
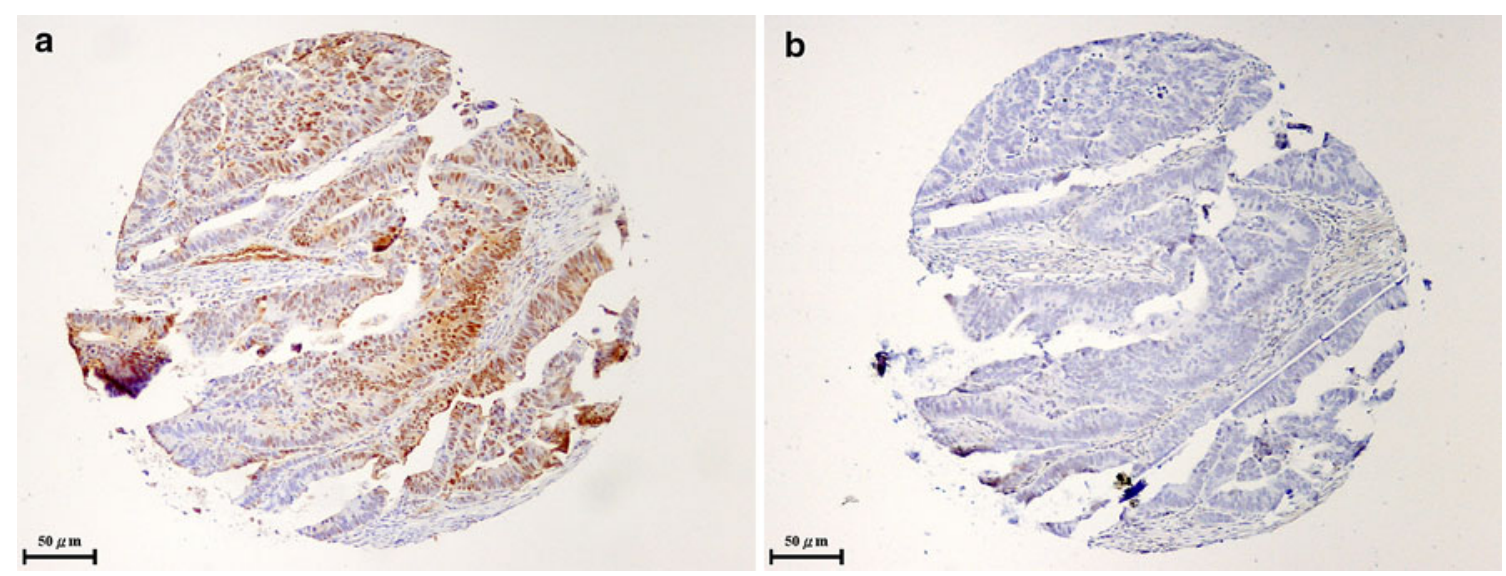

Fig. 1 Immunohistochemical staining of FoxM1 in tissue microarray of colorectal cancers. Anti-FoxM1 antibody was used to stain FoxM1 in colorectal cancer tissues from tissue microarray (a). A negative control was included in a parallel experiment (b). Original magnification, 200× 


\section{Results}

High mRNA level of FoxM1 in ESCC cell lines and tissues

A high level of FoxM1 mRNA was found in ESCC cell lines compared to that in the non-neoplastic squamous cell line NE-1 using qPCR. An increase of 24.34-, 57.45-, 103.72-, 25.81-, and 13.92-fold in the mRNA level of FoxM1 was observed in HKESC-1, HKESC-2, HKESC-3, HKESC-4, and SLMT-1 cells, respectively, compared to that in NE-1 cells (Fig. 2). All of ten ESCC tissues studied showed an increase in FoxM1 mRNA when compared to their corresponding nontumor counterparts. The upregulation of FoxM1 ranged from about 3- (patient 9) to 500-fold (patient 6) (Fig. 3).

High protein level of FoxM1 in ESCC cell lines

The protein level of FoxM1 in cultured cells was analyzed using immunoblot. Non-neoplastic NE-1 cells expressed an undetectable protein level of FoxM1. Except HKESC-3 cells, ESCC cells, including HKESC-1, HKESC-2, HKESC-4, and SLMT-1, showed an elevated protein level of FoxM1 compared to NE-1 cells (Fig. 4).

Low expression of cytoplasmic FoxM1 associated with early-stage ESCC

Immunohistochemistry was performed to investigate the expression and localization of FoxM1 in 64 ESCC tissues and 10 randomly selected nontumor tissues from the same

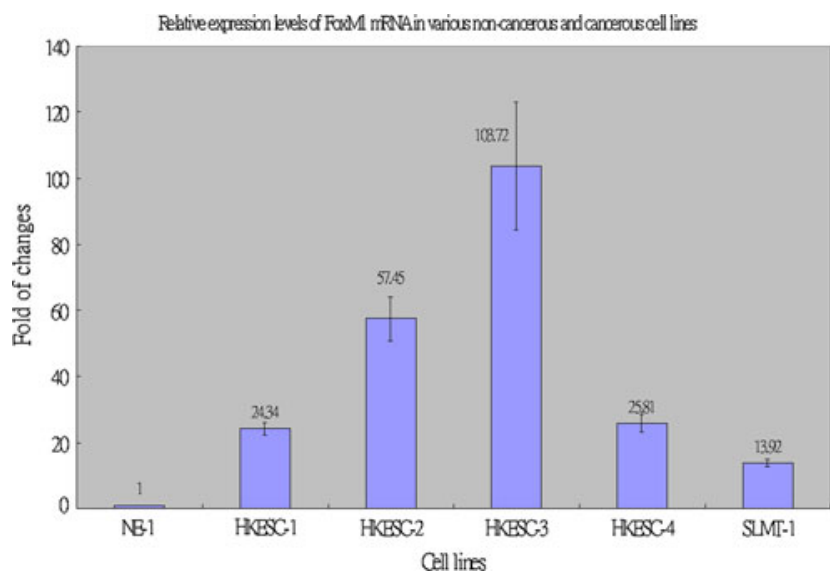

Fig. 2 High mRNA level of FoxM1 in ESCC cell lines. qPCR was performed to investigate the mRNA level of FoxM1 in ESCC cell lines (HKESC-1, HKESC-2, HKESC-3, HKESC-4, and SLMT-1) and the non-neoplastic esophageal cell line NE-1. High mRNA level of FoxM1 was associated with ESCC cells. Each sample was repeated at least in duplicate patient cohort. Cytoplasmic expression of FoxM1 was found in $98.44 \%$ (63/64) of ESCC tissues (Fig. 5), while its nuclear expression was observed in $25 \%$ (16/64) of ESCC

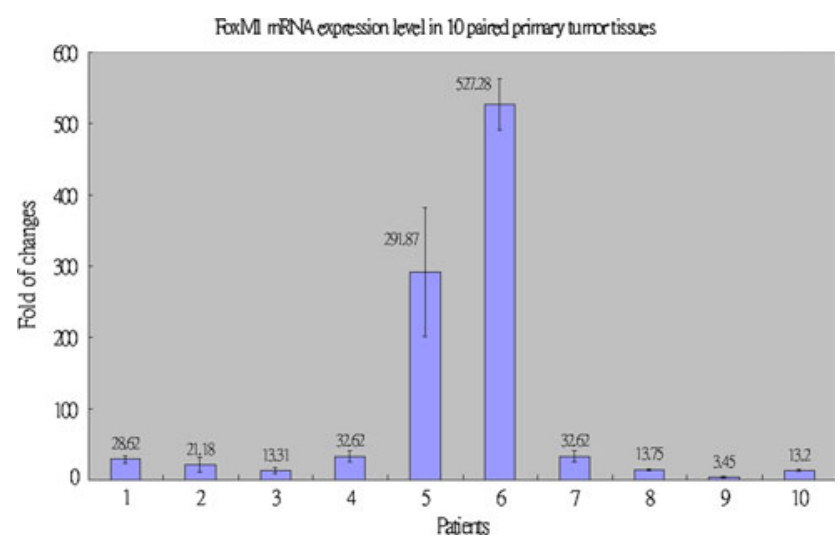

Fig. 3 High mRNA level of FoxM1 in ESCC tissues. qPCR was performed to investigate the mRNA level of FoxM1 in ten pairs of ESCC tissues and their adjacent nontumor tissues. High expression of FoxM1 mRNA was found in all of the ESCC cases. The expression of FoxM1 in nontumor tissues was arbitrarily set to 1 . Each sample was repeated at least in duplicate
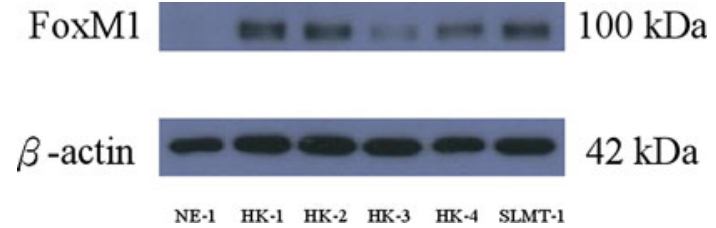

Fig. 4 High protein level of FoxM1 in ESCC cell lines. Immunoblot was performed to examine the protein level of FoxM1 in ESCC cell lines (HKESC-1/HK-1, HKESC-2/HK-2, HKESC-3/HK-3, HKESC4/HK-4, and SLMT-1) and non-neoplastic esophageal cell line NE-1. High protein level of FoxM1 was associated with most ESCC cell lines, except HK-3

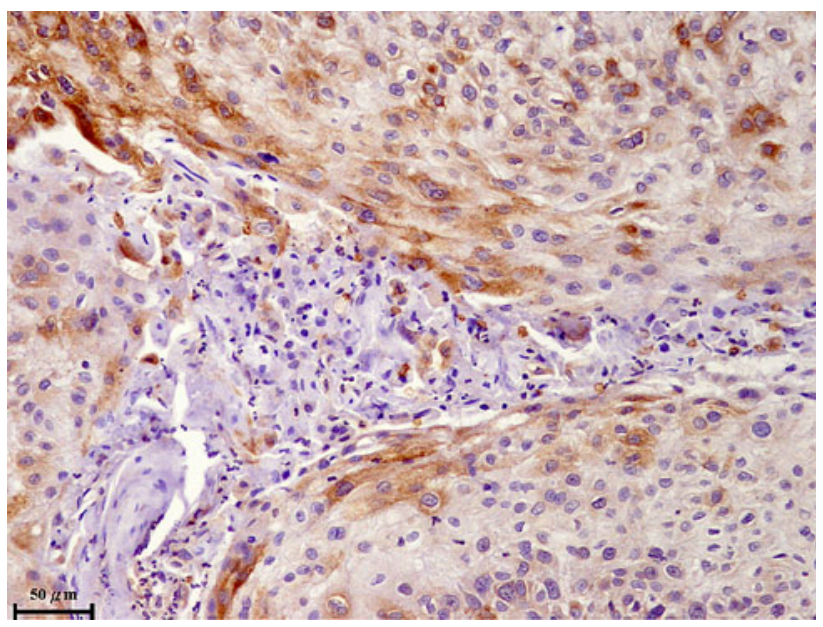

Fig. 5 Cytoplasmic localization of FoxM1 in ESCC tissues. Immunohistochemistry was used to study the expression and localization of FoxM1 in ESCC tissues and most cases of ESCC tissues had cytoplasmic staining of FoxM1. Original magnification, 200× 


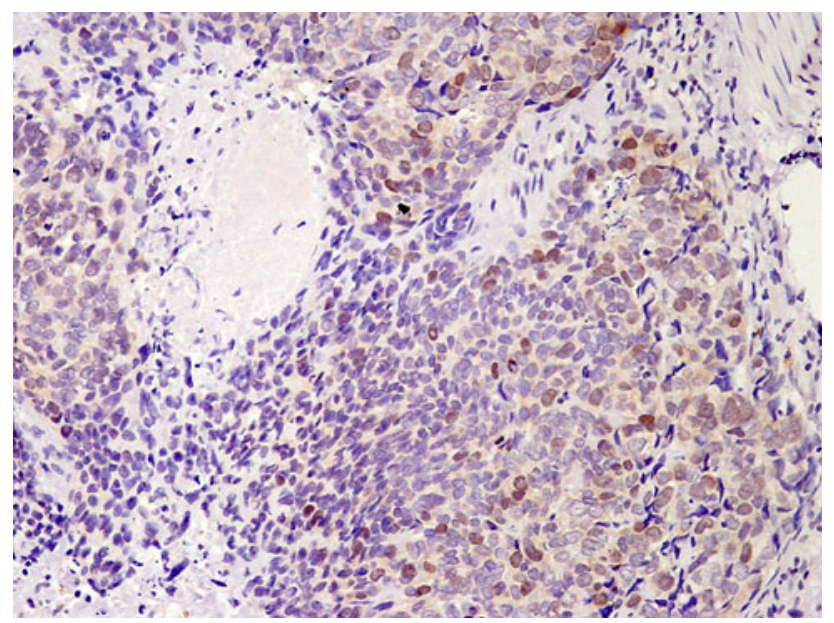

Fig. 6 Nuclear localization of FoxM1 in ESCC tissues. Immunohistochemistry was used to reveal the expression and localization of FoxM1 in ESCC tissues and about 25\% of ESCC cases had tumors with nuclear FoxM1. Original magnification, 200×

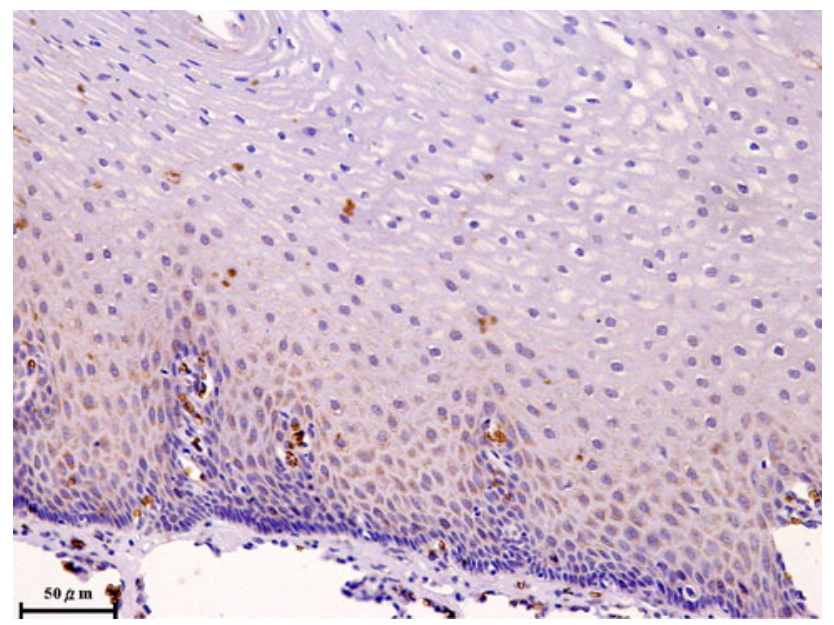

Fig. 7 Localization of FoxM1 in nontumor tissues of ESCC patients. Immunohistochemistry was used to examine the expression and localization of FoxM1 in nontumor tissues from ESCC patients, which showed cytoplasmic FoxM1 expression in the proliferating layer. Original magnification, $200 \times$

tissues (Fig. 6). All nontumor tissues were positive for cytoplasmic FoxM1, whereas 20\% (2/10) of them expressed nuclear FoxM1. Specifically, FoxM1 expression was found mainly in the proliferating layer of the non-neoplastic epithelium and the expression was relatively low in the more differentiated layer (Fig. 7).

Patients with lower expression of cytoplasmic FoxM1 were more likely in the early stage of $\operatorname{ESCC}(P=0.018)$ than those with higher expression $(19 / 37,51.4 \%$ vs. $6 / 27$, $22.2 \%$, respectively) (Table 1). No significant difference in survival after surgery could be found between patients with low expression of cytoplasmic FoxM1 and those with high
Table 1 Correlations between cytoplasmic FoxMl expression and various clinicopathological parameters in ESCC

\begin{tabular}{|c|c|c|c|c|}
\hline \multicolumn{2}{|c|}{ Clinicopathological parameters } & \multirow{2}{*}{$\begin{array}{l}\text { Low } \\
\text { expression }\end{array}$} & \multirow{2}{*}{$\begin{array}{l}\text { High } \\
\text { expression }\end{array}$} & \multirow{2}{*}{$\begin{array}{l}P \text { - } \\
\text { value }\end{array}$} \\
\hline & Subgroups & & & \\
\hline $\begin{array}{c}\text { Age (mean } \\
\text { in years) }\end{array}$ & & 64.3 & 65 & 0.797 \\
\hline \multirow[t]{2}{*}{ Gender } & Female & 11 & 6 & 0.502 \\
\hline & Male & 26 & 21 & \\
\hline \multirow[t]{2}{*}{ Smoking } & Non smoker & 21 & 10 & 0.119 \\
\hline & Smoker & 16 & 17 & \\
\hline \multirow[t]{4}{*}{ Level of Tumor } & Upper & 5 & 5 & 0.895 \\
\hline & Middle & 21 & 16 & \\
\hline & Lower & 9 & 5 & \\
\hline & Double & 2 & 1 & \\
\hline \multirow{3}{*}{$\begin{array}{l}\text { Tumor } \\
\text { differentiation }\end{array}$} & Poor & 10 & 4 & 0.481 \\
\hline & Moderate & 21 & 17 & \\
\hline & Well & 6 & 6 & \\
\hline \multirow[t]{2}{*}{$\mathrm{R}$ catergory } & R0 & 29 & 16 & 0.098 \\
\hline & $\mathrm{R} 1 / \mathrm{R} 2$ & 8 & 11 & \\
\hline \multirow[t]{2}{*}{ T-stage } & Early (T1/T2) & 9 & 4 & 0.35 \\
\hline & $\begin{array}{c}\text { Advanced } \\
\text { (T3/T4) }\end{array}$ & 28 & 23 & \\
\hline \multirow[t]{2}{*}{$\mathrm{N}$-stage } & No & 18 & 8 & 0.126 \\
\hline & N1 & 19 & 19 & \\
\hline \multirow[t]{2}{*}{ M-stage } & M0 & 33 & 25 & 0.645 \\
\hline & Mla/Mlb & 4 & 2 & \\
\hline \multirow{2}{*}{$\begin{array}{l}\text { Overall } \\
\text { pathological } \\
\text { stage }\end{array}$} & Early (Stage I/II) & 19 & 6 & 0.018 \\
\hline & $\begin{array}{l}\text { Advanced } \\
\quad(\text { Stage III/IV) }\end{array}$ & 18 & 21 & \\
\hline
\end{tabular}

expression (14.75 vs. 23.28 months, respectively, $P=$ 0.977) (Fig. 8). Patients with nuclear expression of FoxM1 were younger than those without nuclear FoxM1 (57 vs. 67.13 years, $P<0.001$ ) (Table 2 ). The median postoperative survival for patients with nuclear FoxM1 was similar to those without (14.75 vs. 25.64 months, $P=0.697)$ (Fig. 9).

\section{Discussion}

This study used immunohistochemistry to study the correlations between FoxM1 and various clinicopathological parameters in ESCC patients. Our data show that cytoplasmic FoxM1 is associated with pathological disease stage. This is consistent with the report by Liu et al. [10], which demonstrated that the expression of FoxM1 was higher in patients with high-grade glioma. Another study conducted by Chan et al. [27] also reported that a higher FoxM1 level was significantly associated with 
Table 2 Correlations between nuclear FoxMl expression and various clinicopathological parameters in ESCC

\begin{tabular}{|c|c|c|c|c|}
\hline \multicolumn{2}{|c|}{ Clinicopathological parameters } & \multirow[t]{2}{*}{ Absence } & \multirow[t]{2}{*}{ Presence } & \multirow[t]{2}{*}{$P$-value } \\
\hline & Subgroups & & & \\
\hline $\begin{array}{l}\text { Age (mean } \\
\text { in years) }\end{array}$ & & 67.13 & 57 & $<0.001$ \\
\hline \multirow[t]{2}{*}{ Gender } & Female & 13 & 4 & 0.87 \\
\hline & Male & 35 & 12 & \\
\hline \multirow[t]{2}{*}{ Smoking } & Non smoker & 20 & 11 & 0.06 \\
\hline & Smoker & 28 & 5 & \\
\hline \multirow[t]{4}{*}{ Level of Tumor } & Upper & 9 & 1 & 0.371 \\
\hline & Middle & 27 & 10 & \\
\hline & Lower & 9 & 5 & \\
\hline & Double & 3 & 0 & \\
\hline \multirow{3}{*}{$\begin{array}{l}\text { Tumor } \\
\text { differentiation }\end{array}$} & Poor & 11 & 3 & 0.937 \\
\hline & Moderate & 28 & 10 & \\
\hline & Well & 9 & 3 & \\
\hline \multirow[t]{2}{*}{$\mathrm{R}$ catergory } & R0 & 34 & 11 & 0.874 \\
\hline & $\mathrm{R} 1 / \mathrm{R} 2$ & 14 & 5 & \\
\hline \multirow[t]{2}{*}{ T-stage } & Early (T1/T2) & 9 & 4 & 0.59 \\
\hline & $\begin{array}{c}\text { Advanced } \\
\text { (T3/T4) }\end{array}$ & 39 & 12 & \\
\hline \multirow[t]{2}{*}{$\mathrm{N}$-stage } & No & 19 & 7 & 0.769 \\
\hline & $\mathrm{Nl}$ & 29 & 9 & \\
\hline \multirow[t]{2}{*}{ M-stage } & M0 & 44 & 14 & 0.62 \\
\hline & Mla/Mlb & 4 & 2 & \\
\hline \multirow{2}{*}{$\begin{array}{l}\text { Overall } \\
\text { pathological } \\
\text { stage }\end{array}$} & $\begin{array}{l}\text { Early } \\
\quad \text { (Stage I/II) }\end{array}$ & 18 & 7 & 0.657 \\
\hline & $\begin{array}{l}\text { Advanced } \\
\text { (Stage IMV) }\end{array}$ & 30 & 9 & \\
\hline
\end{tabular}



Fig. 8 Kaplan-Meier survival curves for cytoplasmic FoxM1. Kaplan-Meier survival curves were constructed for patients having high $(n=27)$ or low $(n=37)$ expression of cytoplasmic FoxM1. Logrank test, $P=0.977$ advanced-stage cervical cancer. All of the above findings supported a hypothesis that cytoplasmic FoxM1 might play a role in the progression of ESCC.

Expression of nuclear FoxM1 significantly correlates with the age of ESCC patients, i.e., patients with nuclear FoxM1 are younger than those without nuclear FoxM1. Ly et al. [28] previously compared the expression levels of various genes in fibroblasts from healthy individuals of different ages (young, middle age, and old age) and from patients with Hutchinson-Gilford progeria, which is a rare genetic disease accompanied by accelerated aging. Among the different genes, FoxMl was always downregulated in middle-aged, old-aged, and diseased when compared to young individuals [28]. Nuclear FoxM1 is an active form and regulates the expression of proliferation-related genes like cyclins $[6,7,29,30]$, which are crucial to the cell cycle. It is thus reasonable to find the expression of nuclear FoxM1 in younger ESCC patients since they are likely to have a higher rate of cell proliferation compared to the older patients.

We have found a tendency for patients with a smoking habit to have no expression of nuclear FoxM1. Previous studies have demonstrated that the salivary level of epidermal growth factor (EGF) was 32\% lower in smokers than in nonsmokers [31, 32]. In addition, phosphorylation of EGF receptor in the buccal cavity was impaired in smokers as well [32]. Since the EGF receptor is involved in the mitogen-activated protein kinase (MAPK) pathway [33], this in turn activates FoxM1 [34]. Therefore, smoking-induced reduced salivary EGF level and deficiency in EGF receptor phosphorylation likely inhibit the activation of FoxM1 in esophageal epithelial cells of ESCC patients

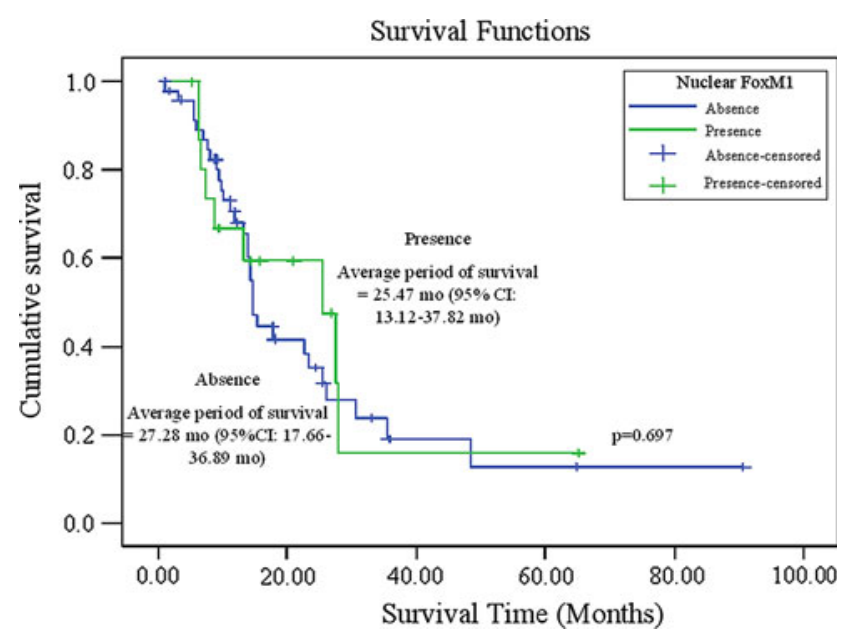

Fig. 9 Kaplan-Meier survival curves for nuclear FoxM1. KaplanMeier survival curves were generated for patients based on the presence $(n=16)$ or absence $(n=48)$ of nuclear FoxM1. Log-rank test, $P=0.697$ 
who smoke. This might finally translate into a significant association between smoking and the absence of nuclear FoxM1 in ESCC patients.

HKESC-3 cells have the highest mRNA level but lowest protein level of FoxM1 when compared to the other studied ESCC cell lines. This could be the result of the presence of post-translation modifications in the FoxM1 gene in ESCC. A review from Calnan and Brunet [35] stated the presence of a wide range of post-translation modifications such as phosphorylation, acetylation, and ubiquitination in the FoxO gene, which is also a member of the Forkhead transcription factor as is FoxM1. Thus, it is possible that a similar posttranslation modification would occur in other members of the Forkhead transcription factor family like FoxM1.

In summary, we have shown that a low cytoplasmic FoxM1 level is correlated with early-stage ESCC and that nuclear FoxM1 expression was found in young ESCC patients. Therefore, FoxM1 is a potential biomarker for late-stage ESCC.

Disclosure The authors have no conflict of interest to declare.

Open Access This article is distributed under the terms of the Creative Commons Attribution Noncommercial License which permits any noncommercial use, distribution, and reproduction in any medium, provided the original author(s) and source are credited.

\section{References}

1. Laoukili J, Stahl M, Medema RH (2007) FoxM1: at the crossroads of ageing and cancer. Biochim Biophys Acta 1775:92-102

2. Yu J, Deshmukh H, Payton JE et al (2011) Array-based comparative genomic hybridization identifies CDK4 and FOXM1 alterations as independent predictors of survival in malignant peripheral nerve sheath tumor. Clin Cancer Res 17:1924-1934

3. Myatt SS, Lam EW (2007) The emerging roles of forkhead box (Fox) proteins in cancer. Nat Rev Cancer 7:847-859

4. Wierstra I, Alves J (2007) FOXM1, a typical proliferation-associated transcription factor. Biol Chem 388:1257-1274

5. Kalin TV, Wang IC, Ackerson TJ et al (2006) Increased levels of the FoxM1 transcription factor accelerate development and progression of prostate carcinomas in both TRAMP and LADY transgenic mice. Cancer Res 66:1712-1720

6. Yoshida Y, Wang IC, Yoder HM et al (2007) The forkhead box M1 transcription factor contributes to the development and growth of mouse colorectal cancer. Gastroenterology 132:1420-1431

7. Zhao YY, Gao XP, Zhao YD et al (2006) Endothelial cell-restricted disruption of FoxM1 impairs endothelial repair following LPSinduced vascular injury. J Clin Invest 116:2333-2343

8. Tan Y, Yoshida Y, Hughes DE et al (2006) Increased expression of hepatocyte nuclear factor 6 stimulates hepatocyte proliferation during mouse liver regeneration. Gastroenterology 130:1283-1300

9. Teh MT, Wong ST, Neill GW et al (2002) FOXM1 is a downstream target of Gli1 in basal cell carcinomas. Cancer Res 62:4773-4780

10. Liu M, Dai B, Kang SH et al (2006) FoxM1B is overexpressed in human glioblastomas and critically regulates the tumorigenicity of glioma cells. Cancer Res 66:3593-3602
11. Kim IM, Ackerson T, Ramakrishna S et al (2006) The Forkhead Box $\mathrm{m} 1$ transcription factor stimulates the proliferation of tumor cells during development of lung cancer. Cancer Res 66: 2153-2161

12. Perou CM, Sorlie T, Eisen MB et al (2000) Molecular portraits of human breast tumours. Nature 406:747-752

13. Sorlie T, Perou CM, Tibshirani R et al (2001) Gene expression patterns of breast carcinomas distinguish tumor subclasses with clinical implications. Proc Natl Acad Sci U S A 98:10869-10874

14. Kalinichenko VV, Major ML, Wang X et al (2004) Foxm1b transcription factor is essential for development of hepatocellular carcinomas and is negatively regulated by the p19ARF tumor suppressor. Genes Dev 18:830-850

15. Jemal A, Bray F, Center MM et al (2011) Global cancer statistics. CA Cancer J Clin 61:69-90

16. Cheung LC, Tang JC, Lee PY et al (2007) Establishment and characterization of a new xenograft-derived human esophageal squamous cell carcinoma cell line HKESC-4 of Chinese origin. Cancer Genet Cytogenet 178:17-25

17. Hu Y, Lam KY, Wan TS et al (2000) Establishment and characterization of HKESC-1, a new cancer cell line from human esophageal squamous cell carcinoma. Cancer Genet Cytogenet 118:112-120

18. Hu YC, Lam KY, Law SY et al (2002) Establishment, characterization, karyotyping, and comparative genomic hybridization analysis of HKESC-2 and HKESC-3: two newly established human esophageal squamous cell carcinoma cell lines. Cancer Genet Cytogenet 135:120-127

19. Tang JC, Wan TS, Wong $\mathrm{N}$ et al (2001) Establishment and characterization of a new xenograft-derived human esophageal squamous cell carcinoma cell line SLMT-1 of Chinese origin. Cancer Genet Cytogenet 124:36-41

20. Zhang H, Jin Y, Chen X et al (2006) Cytogenetic aberrations in immortalization of esophageal epithelial cells. Cancer Genet Cytogenet 165:25-35

21. Lee NP, Leung KW, Cheung $\mathrm{N}$ et al (2008) Comparative proteomic analysis of mouse livers from embryo to adult reveals an association with progression of hepatocellular carcinoma. Proteomics 8:2136-2149

22. Lee NP, Tsang FH, Shek FH et al (2010) Prognostic significance and therapeutic potential of eukaryotic translation initiation factor 5A (eIF5A) in hepatocellular carcinoma. Int J Cancer 127:968-976

23. Lee NP, Chen L, Lin MC et al (2009) Proteomic expression signature distinguishes cancerous and nonmalignant tissues in hepatocellular carcinoma. J Proteome Res 8:1293-1303

24. Lee NP, Leung KW, Wo JY et al (2006) Blockage of testicular connexins induced apoptosis in rat seminiferous epithelium. Apoptosis 11:1215-1229

25. Lee NP, Tong MK, Leung PP et al (2006) Kidney claudin-19: localization in distal tubules and collecting ducts and dysregulation in polycystic renal disease. FEBS Lett 580:923-931

26. Chung Y, Lam AK, Luk JM et al (2007) Altered E-cadherin expression and p120 catenin localization in esophageal squamous cell carcinoma. Ann Surg Oncol 14:3260-3267

27. Chan DW, Yu SY, Chiu PM et al (2008) Over-expression of FOXM1 transcription factor is associated with cervical cancer progression and pathogenesis. J Pathol 215:245-252

28. Ly DH, Lockhart DJ, Lerner RA et al (2000) Mitotic misregulation and human aging. Science 287:2486-2492

29. Kalinichenko VV, Gusarova GA, Tan Y et al (2003) Ubiquitous expression of the forkhead box M1B transgene accelerates proliferation of distinct pulmonary cell types following lung injury. J Biol Chem 278:37888-37894

30. Laoukili J, Kooistra MR, Bras A et al (2005) FoxM1 is required for execution of the mitotic programme and chromosome stability. Nat Cell Biol 7:126-136 
31. Maity P, Biswas K, Roy S et al (2003) Smoking and the pathogenesis of gastroduodenal ulcer-recent mechanistic update. Mol Cell Biochem 253:329-338

32. Wang SL, Milles M, Wu-Wang CY et al (1992) Effect of cigarette smoking on salivary epidermal growth factor (EGF) and EGF receptor in human buccal mucosa. Toxicology 75:145-157

33. Balbis A, Posner BI (2010) Compartmentalization of EGFR in cellular membranes: role of membrane rafts. J Cell Biochem 109:1103-1108
34. Ma RY, Tong TH, Cheung AM et al (2005) Raf/MEK/MAPK signaling stimulates the nuclear translocation and transactivating activity of FOXM1c. J Cell Sci 118:795-806

35. Calnan DR, Brunet A (2008) The FoxO code. Oncogene 27:2276-2288 